\title{
Patrón nodular aleatorio
}

\section{Perilymphatic nodular pattern}

Jorge Carrillo B., MD. (1); Claudia Patricia Zuluaga Gómez, MD. (1); Melissa KallmanN S., MD. ${ }^{(2)}$

${ }^{(1)}$ Radiología - Hospital Universitario Mayor Mederi, Bogotá, Colombia.

${ }^{(2)}$ Medicina Interna - Radiología - Universidad del Rosario, Bogotá, Colombia. Correspondencia: Claudia Patricia Zuluaga Gómez, correo electrónico: patozulua@ gmail.com

Recibido: 20/04/15. Aceptado: 28/04/15.
El término de nódulo se utiliza para describir una opacidad pulmonar redondeada, bien o mal definida, menor de $3 \mathrm{~cm}$ de diámetro. El análisis de las lesiones nodulares del parénquima pulmonar debe incluir tamaño, contornos, densidad y localización. Los nódulos menores de $10 \mathrm{~mm}$ de diámetro se consideran pequeños $(1,2)$. La sociedad Fleishner define como micronódulos a aquellos menores de $3 \mathrm{~mm}$ de diámetro. En general, el término de patrón nodular hace referencia a lesiones nodulares pequeñas, múltiples, en el parénquima pulmonar. La localización de los nódulos en relación con las estructuras del lobulillo pulmonar secundario, permite estrechar el diagnóstico diferencial y categoriza el patrón nodular en: perilinfático, aleatorio y centrilobulillar (1).

Los nódulos aleatorios pueden evidenciarse en relación con la superficie pleural, los vasos pulmonares y los septos interlobulillares, pero no tienen una localización consistente o una relación definida con una estructura anatómica particular. En general el patrón nodular aleatorio es bilateral y simétrico.

El diagnóstico diferencial de patrón nodular aleatorio debe incluir entidades infecciosas (tuberculosis con diseminación hematógena) y neoplásicas (enfermedad metastásica) entre otras (tabla 1).

\section{Tuberculosis con diseminación hematógena (miliar)}

Se caracteriza por nódulos con densidad de tejido blando, de contornos bien definidos y diámetro variable (2-7 $\mathrm{mm})$, aunque en la mayoría de casos los nódulos tienen diámetros de 2-3 mm. En general predomina en lóbulos superiores. La histoplasmosis diseminada puede presentar un patrón indistinguible de la tuberculosis miliar (figura 1).

\section{Neoplasia metastásica}

La enfermedad metastásica al parénquima pulmonar puede manifestarse con nódulos de tamaño variable (pequeños y grandes) $\mathrm{y}$ clásicamente exhiben densidad de tejido blando y contornos bien definidos. Ocasionalmente y de acuerdo con las características del tumor primario, las metástasis presentan signo del "halo", cavitación o calcificación. En el patrón nodular aleatorio relacionado con enfermedad metastásica, los nódulos pueden definirse en relación con los vasos pulmonares y predominan en la periferia del pulmón, pero no tienen predilección por una estructura del lobulillo pulmonar secundario (figura 2). 
Tabla 1. Diagnósticos diferenciales.

\begin{tabular}{|c|c|}
\hline Neoplasia primaria & Infección \\
\hline $\begin{array}{l}\text { - } \text { Adenocarcinoma } \\
\text { - } \text { Linfoma } \\
\text { - } \text { Tumor - Lets } \\
\text { patrónocarcinoma con crecimiento } \\
\text { lepídico }\end{array}$ & $\begin{array}{l}\text { - Tuberculosis } \\
\text { - Neumonía viral (Varicela) } \\
\text { - Histoplasmosis } \\
\text { - Aspergilosis invasiva } \\
\text { - Papilomatosis }\end{array}$ \\
\hline Neoplasia secundaria & Enfermedad exposicional \\
\hline \multirow{3}{*}{$\begin{array}{l}\text { - } \text { Melanoma } \\
\text { - Turcinoma de tiroides } \\
\text { gastrointestinal } \\
\text { - Seno } \\
\text { - Coriocarcinoma } \\
\text { - Seminoma }\end{array}$} & - Silicosis \\
\hline & Otras \\
\hline & $\begin{array}{l}\text { - Sarcoidosis } \\
\text { - Amiloidosis } \\
\text { - Histiocitosis de células de } \\
\text { Langerhans } \\
\text { - Microlitiasis alveolar }\end{array}$ \\
\hline
\end{tabular}
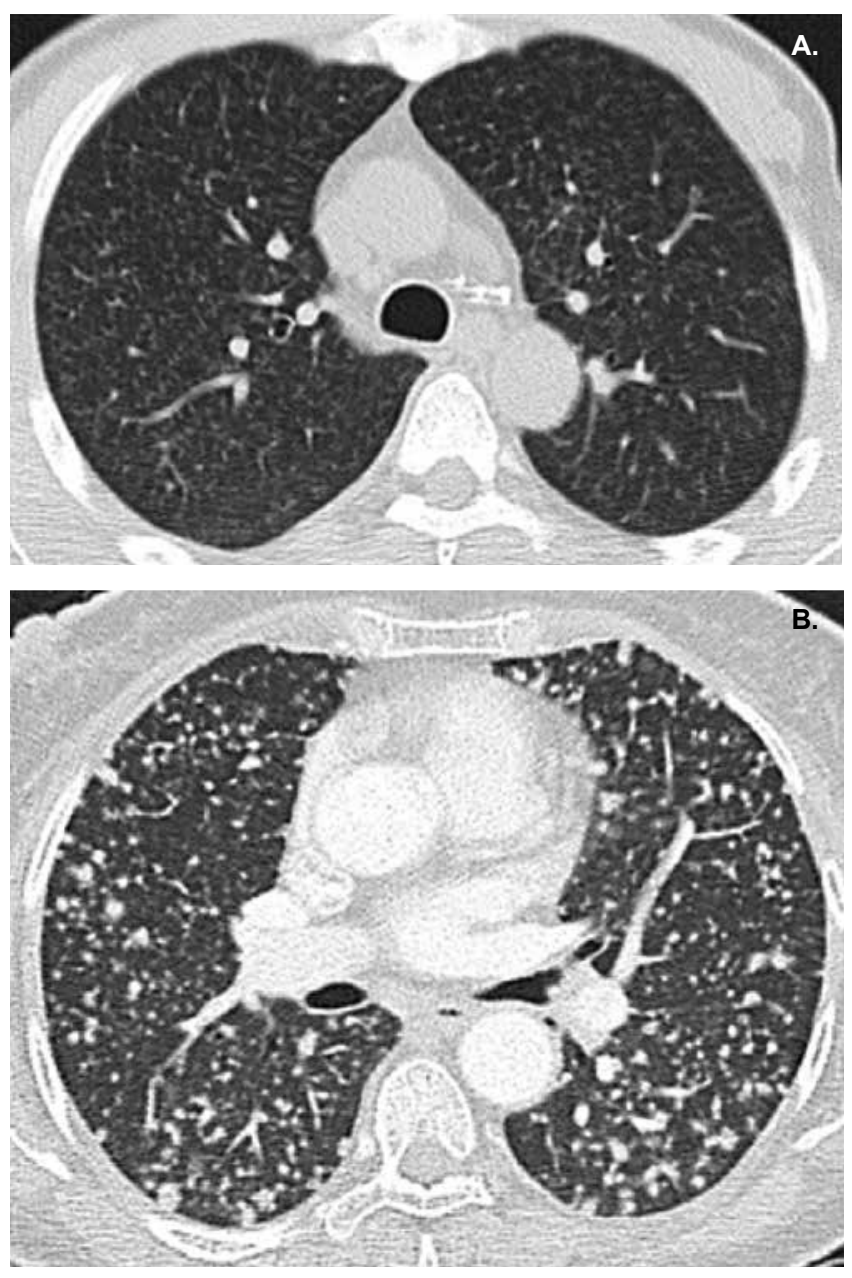

Figura 1. Tuberculosis miliar con diseminación hematógena. A y $\mathrm{B}$ : Corte axial y reconstrucción coronal. Micronódulos (menores de $3 \mathrm{~mm}$ de diámetro), con densidad de tejido blando, de contornos bien definidos y distribución aleatoria.
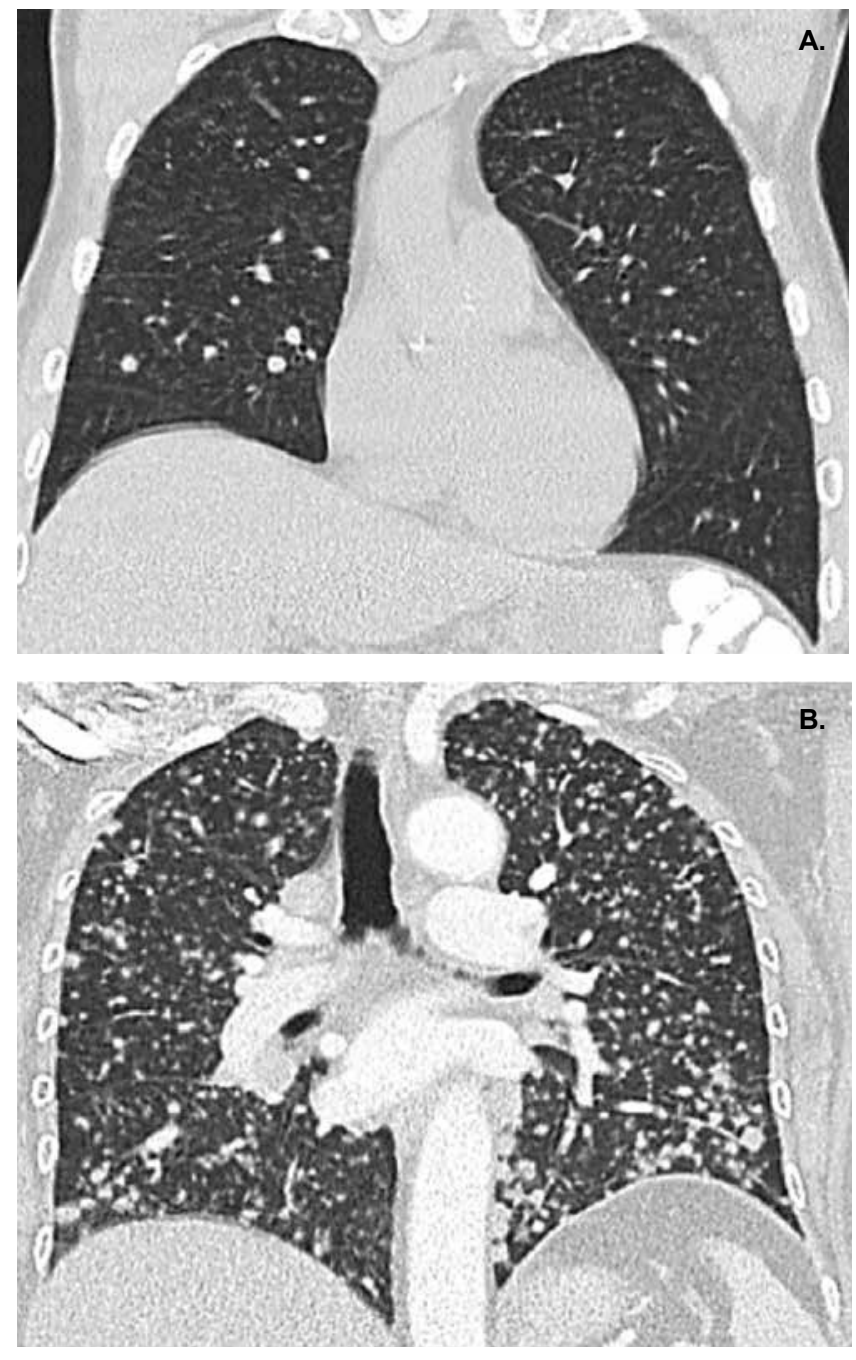

Figura 2. Metastástasis de cáncer de seno con diseminación hematógena. A y B: corte axial y reconstrucción coronal. Nódulos pequeños ( $3-8 \mathrm{~mm}$ de diámetro), con densidad de tejido blando, de contornos bien definidos y distribución aleatoria.

\section{Bibliografía}

1. Webb WR, Müller NL, Naidich DP. High Resolution CT of the Lung. Fifth Edition. Lippincott Williams \& Wilkins. 2014;112-16 p.

2. Boitsios G, Bankier AA, Eisenberg RL. Diffuse pulmonary nodules. AJR Am J Roentgenol. 2010;194(5):W354-66.

3. MacMahon H, Austin JH, Gamsu G, Herold CJ, Jett JR, Naidich DP, et al. Guidelines for management of small pulmonary nodules detected on CT scans: a statement from the Fleischner Society. Radiol. 2005;237(2):395-400. 